\title{
A Prominent Increase in Slow Wave Sleep after PAP Therapy
}

\section{Muhammad Riaz ${ }^{1 *}$ and Gaurav Nigam ${ }^{1}$}

${ }^{1}$ Twin Cities Community Hospital, 1100 Las Tablas Road, Templeton, CA 93465, USA

${ }^{2}$ Clay County Hospital, Flora, IL 62839, USA

\begin{abstract}
Sleep disturbances are common in patients with chronic pain syndrome, and coexistent obstructive sleep apnea (OSA) in such patients could further compromise the quality of sleep and increase sleep fragmentation. Here we present an unusual case of profound increase in slow wave sleep as noted during the sleep study and discuss the potential causes for this observed polysomnograhic phenomenon.
\end{abstract}

Keywords: Obstructive sleep apnea; CPAP titration; Increase delta sleep; Sleep deprivation; Gabapentin; Slow wave sleep

\section{Case Vignette}

A 43-year-old female with past medical history of attention deficit hyperactivity disorder of inattentive type, depression, chronic pain syndrome, and diabetes mellitus presented to sleep disorder center for evaluation of excessive daytime sleepiness (EDS). She denied consumption of cigarettes, alcohol or recreational drugs. Her home medications included Metformin, Gabapentin, Bupropion, Venlafaxine, Buspirone and Methylphenidate. General physical exam was consistent with crowded oropharynx, (Mallampati class 3 with grade 1 tonsils), but a normal cardiovascular as well as neurologic exam. She underwent attended diagnostic in laboratory polysomnogram (PSG) which revealed OSA with an apnea hypopnea index (AHI) of 9.3 events/hour, and oxygen nadir of $90 \%$ (Table 1). Her percentage of total sleep time (TST) in non-rapid eye movement sleep in stage 3 (N3) increased from $15.3 \%$ in diagnostic PSG (Figures 1 and 2) to $58.1 \%$ (Figures 3 and 4 ) in titration study and up to $86.3 \%$ in re-titration study (Figures 5 and 6). Her titration study was done two weeks following diagnostic PSG and a continuous positive airway pressure (CPAP) setting of $6 \mathrm{~cm}$ of water was recommended. She had a re-titration study 9 months later due to CPAP intolerance and lack of significant improvement in OSA symptoms. This re-titration study recommended a bi-level positive airway pressure (BiPAP) of $12 / 7 \mathrm{~cm}$ of water. The patient was started on Gabapentin $900 \mathrm{mg}$ daily 2-3 months prior to her re-titration study. Other than initiation of Gabapentin, no changes occurred in terms of her body weight, clinical comorbidities or use of prescription/nonprescription medications between subsequent sleep studies.

\section{Discussion}

The cause of infrequent large increase in slow wave sleep in this case appears to be multifactorial.

\section{First}

Acute sleep deprivation and sleep fragmentation can present concurrently in patients with OSA and the treatment of OSA not only improves sleep fragmentation but also enhances the overall quality of sleep. It has been well reported that stage REM and N3 are the two most common sleep stages which increase after first night of CPAP, and stage N3 usually takes precedence over Stage REM after a night of sleep deprivation [1]. Given her history of untreated OSA, our patient has chronic partial sleep deprivation. Added to this; she reported sleeping only 1-2 hours prior to her re-titration study which could possibly explain increased slow wave sleep (N3 lasting $86 \%$ of total sleep time) during the re-titration study. A short sleep latency of 3 minutes on this study further supports acute sleep deprivation (compared to her sleep latency of 33 minutes on the baseline study). Given that her stage N3 was also increased between the baseline study and the first titration

\begin{tabular}{|c|c|c|c|}
\hline Sleep Variables & $\begin{array}{c}\text { Diagnostic } \\
\text { PSG }\end{array}$ & PAP Titration & PAP Re-titration \\
\hline AHI (events/hr) & 9.3 & 9.3 & 4.9 \\
\hline SPO $^{2}$ nadir (\%) & 90 & 93 & 96 \\
\hline Sleep latency (min) & 33 & 60 & 1.5 \\
\hline $\begin{array}{c}\text { Total sleep time (TST) } \\
\text { in stage N1 (\%) }\end{array}$ & 7.7 & 0.9 & 2.2 \\
\hline $\begin{array}{c}\text { Total sleep time (TST) } \\
\text { in stage N2 (\%) }\end{array}$ & 77 & 41 & 11.4 \\
\hline $\begin{array}{c}\text { Total sleep time (TST) } \\
\text { in stage N3 (\%) }\end{array}$ & 15.3 & 58 & 86.3 \\
\hline $\begin{array}{c}\text { Total sleep time (TST) } \\
\text { in stage REM (\%) }\end{array}$ & 0 & 0 & 0 \\
\hline
\end{tabular}

Table 1: Polysomnogram results. REM: Rapid eye movement sleep; N1, N2, N3: Stage 1, 2, 3 of non rapid eye movement sleep; $\mathrm{AHI}$ : Apnea hypopnea index; SPO${ }^{2}$ Lowest oxygen saturation.

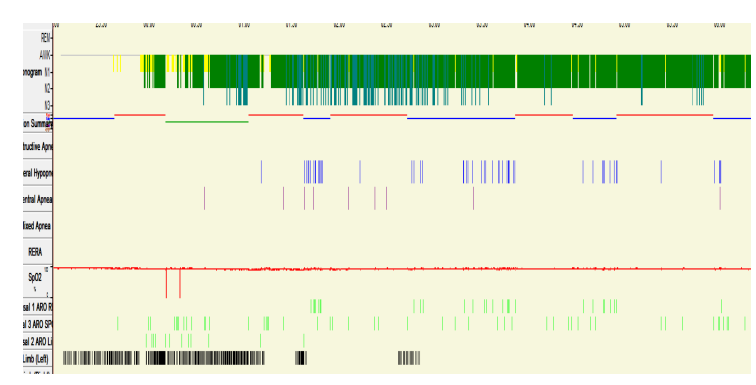

Figure 1: Baseline polysomnogram hypnogram (Yellow N1, Green N2, and Dark Green N3).

study (N3 lasting $58 \%$ of total sleep time), this incremental escalation during re-titration argues against presence of sleep deprivation as the only etiology for increase in the proportion of slow wave sleep. As first night of CPAP titration improves sleep architecture and increases slow wave sleep, increase in $\mathrm{N} 3$ on titration study likely a result of CPAP titration $[1,2]$.

*Corresponding author: Muhammad Riaz, Twin Cities Community Hospital, 1100 Las Tablas Road, Templeton, CA 93465, USA, Tel: 8054343500; E-mail: hmriazmalik08@gmail.com

Received March 28, 2016; Accepted May 05, 2016; Published May 07, 2016

Citation: Riaz M, Nigam G (2016) A Prominent Increase in Slow Wave Sleep after PAP Therapy. J Pulm Respir Med 6: 342. doi:10.4172/2161-105X.1000342

Copyright: ( 2016 Riaz M, et al. This is an open-access article distributed under the terms of the Creative Commons Attribution License, which permits unrestricted use, distribution, and reproduction in any medium, provided the original author and source are credited. 
Citation: Riaz M, Nigam G (2016) A Prominent Increase in Slow Wave Sleep after PAP Therapy. J Pulm Respir Med 6: 342. doi:10.4172/2161105X.1000342

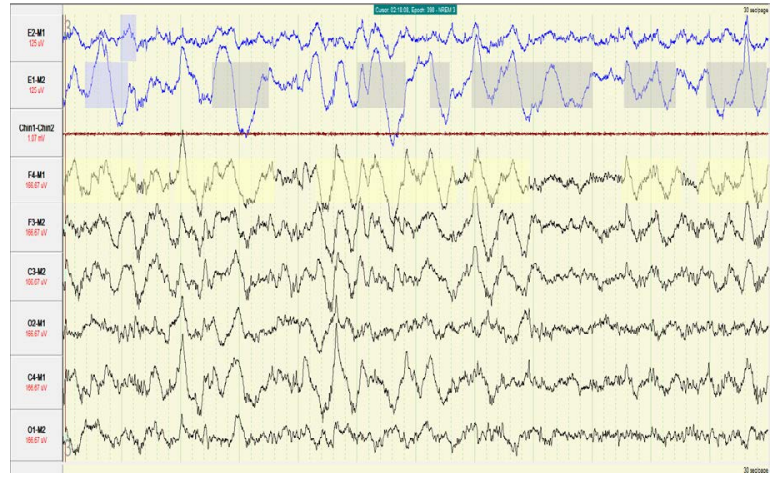

Figure 2: An epoch of diagnostic polysomnogram showing delta sleep.

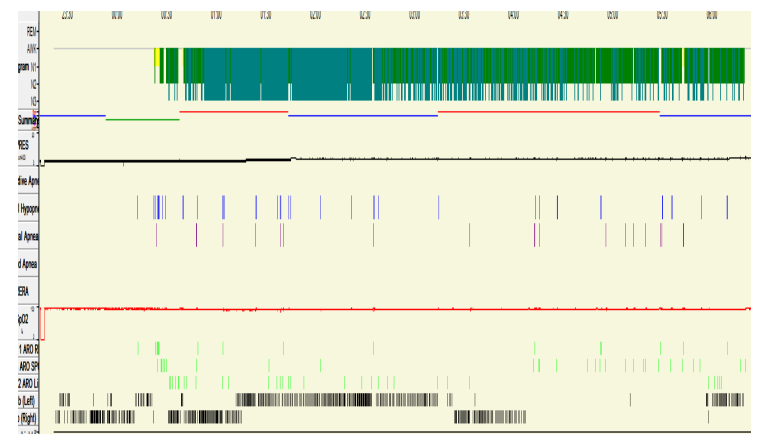

Figure 3: Titration polysomnogram hypnogram (Yellow N1, Green N2, and Dark Green N3).

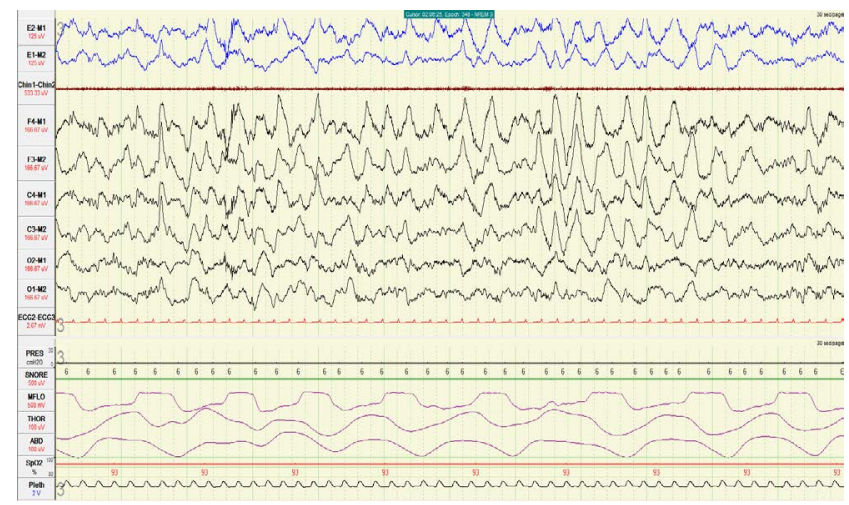

Figure 4: An epoch of titration polysomnogram showing delta sleep.

\section{Second}

Gabapentin is one of the commonly used medications for neuropathic pain. This medication has been reported to increase slow wave sleep with one study reporting a 5 percent increase from baseline and another study reporting 12 minutes of increase from the baseline duration respectively $[3,4]$. Our patient was started on Gabapentin 900 mg daily for chronic pain syndrome 2-3 months before her re-titration study and she denied taking this medication at the time of her baseline and titration sleep studies. As previous studies have established that both Pregabalin and Gabapentin can cause increased slow wave sleep, this N3 surge in re-titration could partially be attributed to Gabapentin.

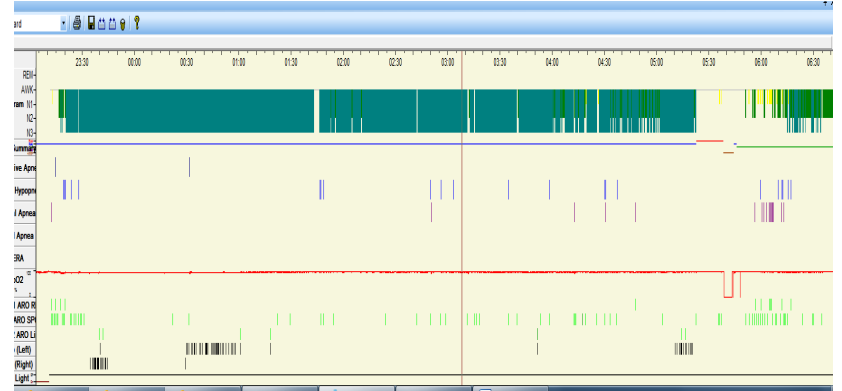

Figure 5: Re-titration polysomnogram hypnogram (Yellow N1, Green N2, and Dark Green N3).

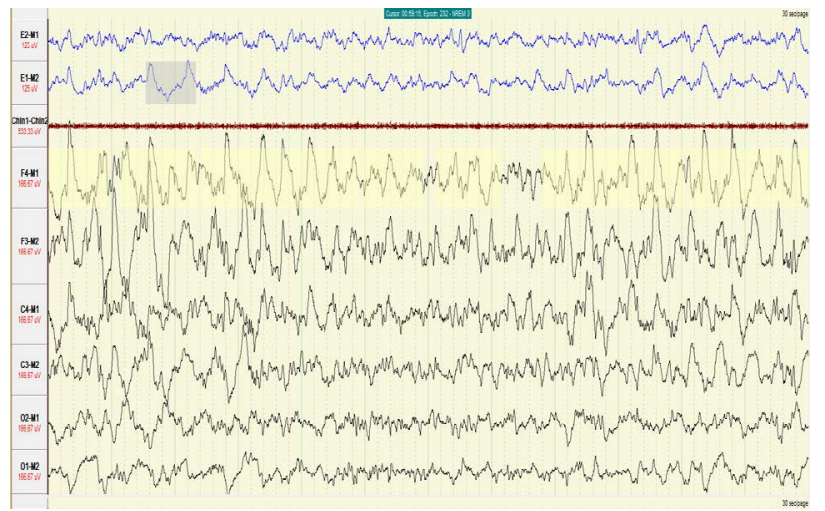

Figure 6: An epoch of re-titration polysomnogram showing delta sleep.

Nevertheless, this percentage increase in N3 sleep appears out of proportion to what has been reported in the literature. Our patient was also taking Bupropion (minimal effect on sleep architecture) [5], Venlafaxine (suppresses REM sleep and minimal effect on delta sleep) [6], Buspirone (decreases delta sleep) [7], and Methylphenidate (minimal effect on sleep architecture) [8] which are not known to increase stage N3 sleep.

\section{Third}

As reported in the literature, OSA patients can have increased slow wave sleep on their first night of CPAP titration. This was our first impression after looking at this patient's titration study where stage N3 sleep was increased to $58 \%$ from baseline of $15 \%$. When compared with re-titration, which has significant prolongation in proportion of stage N3 sleep, it is apparent that the etiology of this large increase in slow wave sleep is multifactorial. Increase N3 on first night of CPAP was likely due to treatment of OSA. Prolongation of N3 to $86 \%$ on re-titration was most likely a combination of acute sleep deprivation, Gabapentin and treatment of OSA.

At least 100 million Americans are suffering from chronic pain and associated healthcare cost is considered higher than heart disease, diabetes and malignancy $[9,10]$. A large number of chronic pain patients (41\%) demonstrate poor sleep quality and as much as 60\% patients with chronic neuropathic pain suffer from sleep disturbances $[11,12]$. CPAP not only alleviate cardiovascular complications associated with OSA but also improves quality of life by decreasing daytime sleepiness [13]. There is also a possible analgesic role of CPAP in improving pain tolerance in chronic pain patients [14]. Of note, obesity is another growing major 
Citation: Riaz M, Nigam G (2016) A Prominent Increase in Slow Wave Sleep after PAP Therapy. J Pulm Respir Med 6: 342. doi:10.4172/2161105X.1000342

health problem in United States with estimated prevalence of 35\% [15]. Obesity and chronic pain do have interplay between each other [16], and obesity is the strongest risk factor for OSA [17]. Therefore screening for OSA can be very helpful in this demographic especially with coexistent obesity. As chronic neuropathic patients are often taking medications like Gabapentin for their neuropathic pain and PAP treatment of OSA in such patients with their concomitant use of Gabapentin could have a synergistic effect on their sleep quality.

\section{Conclusion}

Recognition of sleep disordered breathing in chronic pain patients can be of utmost importance as CPAP can not only improve sleep quality but also could have analgesic effect. Chronic pain patients who are taking medications like Gabapentin could have synergistic effect on sleep quality when combined with PAP therapy. Future research is needed to further investigate the effect of increase slow wave sleep on chronic pain, obesity, and Non-REM parasomnias.

\section{Acknowledgement}

The institution where the work was primarily performed is Sleep Disorders Center, University of Michigan, Ann Arbor, MI 48109, USA.

\section{References}

1. Berry RB (2012) Fundamentals of sleep medicine. In: Berry RB (ed.) Sleep architecture parameters, normal sleep, and sleep loss. Philadelphia: Elsevier Saunders pp: 88

2. Issa FG, Sullivan CE (1986) The immediate effects of nasal continuous positive airway pressure treatment on sleep pattern in patients with obstructive sleep apnea syndrome. Electroencephalogr Clin Neurophysiol 63: 10-17.

3. Foldvary-Schaefer N, De Leon Sanchez I, Karafa M, Mascha E, Dinner D, et al. (2002) Gabapentin increases slow-wave sleep in normal adults. Epilepsia 43: $1493-1497$

4. Winkelman JW, Bogan RK, Schmidt MH, Hudson JD, DeRossett SE, et al. (2011) Randomized polysomnography study of gabapentin enacarbil in subjects with restless legs syndrome. Mov Disord 26: 2065-2072.

5. Holshoe JM (2009) Antidepressants and sleep: a review. Perspect Psychiatr Care 45: 191-197.

6. Salín-Pascual RJ, Galicia-Polo L, Drucker-Colín R (1997) Sleep changes after 4 consecutive days of venlafaxine administration in normal volunteers. J Clin Psychiatry 58: 348-350.

7. Biard K, Douglass AB, De Koninck J (2015) The effects of galantamine and buspirone on sleep structure: Implications for understanding sleep abnormalities in major depression. J Psychopharmacol 29: 1106-1111.

8. Sobanski E, Schredl M, Kettler N, Alm B (2008) Sleep in adults with attention deficit hyperactivity disorder (ADHD) before and during treatment with methylphenidate: a controlled polysomnographic study. Sleep 31: 375-381.

9. Nahin RL (2015) Estimates of pain prevalence and severity in adults: United States, 2012. J Pain 16: 769-780.

10. Pizzo PA, Clark NM (2012) Alleviating suffering 101--pain relief in the United States. N Engl J Med 366: 197-199.

11. Gustorff B, Dorner T, Likar R, Grisold W, Lawrence K, et al. (2008) Prevalence of self-reported neuropathic pain and impact on quality of life: a prospective representative survey. Acta Anaesthesiol Scand 52: 132-136.

12. Karaman S, Karaman T, Dogru S, Onder Y, Citil R, et al. (2014) Prevalence of sleep disturbance in chronic pain. Eur Rev Med Pharmacol Sci 18: 2475-2481.

13. Gay P, Weaver T, Loube D, Iber C, Positive Airway Pressure Task Force, et al. (2006) Evaluation of positive airway pressure treatment for sleep related breathing disorders in adults. Sleep 29: 381-401.

14. Onen SH, Onen F, Albrand G, Decullier E, Chapuis F, et al. (2010) Pain tolerance and obstructive sleep apnea in the elderly. J Am Med Dir Assoc 11: 612-616.

15. Ogden CL, Carroll MD, Kit BK, Flegal KM (2014) Prevalence of childhood and adult obesity in the United States, 2011-2012. JAMA 311: 806-814.

16. Narouze S, Souzdalnitski D (2015) Obesity and chronic pain: systematic review of prevalence and implications for pain practice. Reg Anesth Pain Med 40: 91 111.

17. Young T, Skatrud J, Peppard PE (2004) Risk factors for obstructive sleep apnea in adults. JAMA 291: 2013-2016. 